\title{
GIẢI MÃ TIÊU ĐỀ DẠNG CÂU HỎI TRÊN BÁO CHÍ (TRÊN NGỮ LIỆU BÁO TIẾNG NGA)
}

\author{
Vũ Thị Chín* \\ Khoa Ngôn ngũ và Văn hóa Nga, Trường Đại học Ngoại ngũu, ĐHQGHN, \\ Phạm Văn Đồng, Cầu Giấy, Hà Nội, Việt Nam \\ Nhận bài ngày 26 tháng 03 năm 2018 \\ Chỉnh sửa ngày 25 tháng 05 năm 2018; Chấp nhận đăng ngày 28 tháng 05 năm 2018
}

Tóm tắt: Mối quan hệ giữa nhà báo và bạn đọc được thể hiện rất rõ trong các tiêu đề dạng câu hỏi. Các câu hỏi trên báo chí không đặt ra mục đích nhận được thông tin phản hồi, ngược lại bản thân chúng đã chứa đựng những thông tin quan trọng. Đó chỉ là cái cớ để các nhà báo hướng tới mục đích tiếp cận gần hơn với độc giả, mong muốn độc giả tham gia vào vấn đề của họ, là người chất vấn, đối thoại cùng họ. Đó cũng là cách nhà báo chuẩn bị tinh thần cho độc giả tiếp nhận một số thông tin, thúc giục họ tiếp cận bài báo, tìm sự đồng tình hay chung ý nghĩ phản đối của họ. Phân tích các dạng câu hỏi trong các tiêu đề và tìm ra những thông điệp, ẩn ý ngầm... mà tác giả muốn truyền tải là mục đích của bài viết này.

Tù khóa: ngôn ngữ báo chí, tiêu đề, câu hỏi, thông điệp

\section{1. Đặt vấn đề}

Xu hướng chung của báo chí hiện đại là "cởi mở, thân thiện với bạn đọc"; giữa nhà báo và bạn đọc hình thành mối quan hệ qua lại khăng khít. Mối quan hệ này được thể hiện rất rõ nét trên báo chí trong các tiêu đề dạng câu hỏi. Thông thường, trong giao tiếp, các câu hỏi thường đòi hỏi câu trả lời trực tiếp. Tuy nhiên, bản chất của loại hình văn viết (trong đó có báo chí) là không thể nhận được câu trả lời trực tiếp của độc giả, vì thế đặc tính cơ bản của các câu hỏi trên báo chí không đặt ra mục đích nhận được thông tin phản hồi, ngược lại bản thân các câu hỏi đã chứa đựng những thông tin quan trọng. Các câu hỏi trong tiêu đề trên báo chí dường như chỉ là cái cớ để các nhà báo hướng tới mục đích tiếp cận gần hơn với độc giả, mong muốn độc giả tham gia vào vấn đề của họ, là người chất vấn, đối thoại cùng họ.

* ĐT.: 84-904511498

Email: vuthichin191@gmail.com
Trong một số trường hợp, câu hỏi là cách nhà báo chuẩn bị tinh thần cho độc giả tiếp nhận một số thông tin, thúc giục họ "đối thoại" với nhà báo, tìm "làn sóng" chung với họ, tìm sự đồng tình hay chung ý nghĩ phản đối của họ. Câu hỏi còn tạo ra phương thức giao tiếp sống động, nhưng tự nhiên, mộc mạc của nhà báo với độc giả. Chính vì vậy, tiêu đề dạng câu hỏi luôn được các nhà báo sử dụng như một "chiến thuật" lợi hại, một "bảo bối” để thu hút sự chú ý, quan tâm, theo dõi của độc giả.

Để “Giải mã câu hỏi trong các tiêu đề báo", chúng tôi sử dụng thủ pháp thống kê, so sánh, phương pháp miêu tả để phân loại, phân tích và tổng hợp chức năng, vai trò của các tiêu đề báo có dạng câu hỏi trong tiếng Nga và tìm ra những thông điệp (đặc biệt là thông điệp ngầm, ẩn ý...) mà tác giả muốn truyền tải tới độc giả thông qua những câu hỏi đó. 


\section{Nội dung nghiên cứu}

\subsection{Tiêu đề báo: chức năng, nhiệm vu}

Ngôn ngữ báo chí có đặc trưng là ngôn ngữ của thông tin, sự kiện, ngôn ngữ định lượng (chứ không phải định tính). Ngôn từ trong tiêu đề báo thường ngắn gọn, cô đọng, súc tích, nhưng đồng thời phải truyền tải được lượng thông tin tối đa trong khuôn khổ hạn hẹp của tờ báo. Chức năng quan trọng và cơ bản nhất của tiêu đề là tạo ra sự khác biệt, thu hút sự chú ý của bạn đọc. Một tiêu đề tốt cần đạt được các tiêu chí sau:

- Tạo tò mò (độc, lạ, hấp dẫn),

- Cung cấp thông tin (trực tiếp hay gián tiếp) về nội dung, chủ đề của bài báo,

- Hứa hẹn về một câu trả lời cho một câu hỏi/ bức xúc/ thắc mắc của độc giả mang tính thời sự hoặc một giải pháp cho một vấn đề...

Tiêu đề chính là cầu nối giữa báo chí và độc giả, là bộ mặt của bài báo, là những ấn tượng ban đầu mà nhà báo dành cho bạn đọc. Sự thành công của bài báo một phần là nhờ vào tiêu đề của bài báo đó. Đây chính là mảnh đất mầu mỡ để các nhà báo-nhà ngôn ngữ thỏa sức sáng tạo. Cùng với một loạt các thủ pháp ngôn ngữ khác (chơi chữ, điệp từ, điệp ngữ, từ đồng nghĩa, trái nghĩa...), sử dụng câu hỏi là một trong những thủ pháp yêu thích và được sử dụng rộng rãi trong các tiêu đề báo chí.

\subsection{Tiêu đề dạng câu hỏi trên báo chí Nga}

Khảo sát tiêu đề trên báo chí Nga chúng tôi nhận thấy rằng, tiêu đề dạng câu hỏi có số lượng không nhỏ. Mỗi số báo nói chung đều có một vài bài có tiêu đề dạng câu hỏi, nhưng tuần báo uy tín và có số lượng phát hành lớn nhất nước Nga Аргументы u Факmbl $(A u \Phi)$ - Luận chứng và Sụ kiện (AiF) phần lớn các bài báo có tiêu đề là câu hỏi. Trong 12 số báo phát hành quý 1 năm 2018, trung bình mỗi số có tới vài chục bài báo có tiêu đề là câu hỏi, chiếm hơn $73 \%$, (nghĩa là nhiều gấp tới 3 lần so với bài có tiêu đề dạng khác).

\begin{tabular}{|c|c|c|c|c|}
\hline Ngày tháng & Số & $\begin{array}{c}\text { Tổng } \\
\text { số } \\
\text { bài }\end{array}$ & $\begin{array}{c}\text { Tiêu } \\
\text { đề có } \\
\text { câu } \\
\text { hỏi }\end{array}$ & $\begin{array}{c}\text { Tỉ } \\
\text { trọng }\end{array}$ \\
\hline $10 / 01 / 2018$ & №1-2 & 80 & 62 & $77,5 \%$ \\
\hline $17 / 01 / 2018$ & № 3 & 79 & 60 & $75,9 \%$ \\
\hline $24 / 01 / 2018$ & № 4 & 77 & 60 & $77,9 \%$ \\
\hline $31 / 01 / 2018$ & № 5 & 73 & 57 & $78 \%$ \\
\hline $07 / 02 / 2018$ & № 6 & 66 & 55 & $83,3 \%$ \\
\hline $14 / 02 / 2018$ & № 7 & 71 & 61 & $85,9 \%$ \\
\hline $21 / 02 / 2018$ & № 8 & 42 & 27 & $64,2 \%$ \\
\hline $28 / 02 / 2018$ & № 9 & 62 & 42 & $67,7 \%$ \\
\hline $07 / 03 / 2018$ & № 10 & 55 & 30 & $54,5 \%$ \\
\hline $14 / 03 / 2018$ & № 11 & 74 & 53 & $71,6 \%$ \\
\hline $21 / 03 / 2018$ & № 12 & 62 & 35 & $56,4 \%$ \\
\hline Tổng cộng & 12 số & $\mathbf{7 4 1}$ & $\mathbf{5 4 2}$ & $\mathbf{7 3 , 1 \%}$ \\
\hline
\end{tabular}

Khi đọc báo, nhiệm vụ khó khăn nhất của độc giả là "giải mã" tiêu đề báo - một phát ngôn/mệnh đề/tuyên bố/thông điệp ngắn gọn (đôi khi hơi bí ẩn): nó không chỉ truyền tải thông tin nào đó, mà còn là đánh giá riêng của tác giả về vấn đề nêu ra trong bài viết. Để có cái nhìn bao quát và chung nhất về các câu hỏi trong tiêu đề báo chí Nga và giải mã chúng, chúng tôi không chỉ nghiên cứu tiêu đề báo $A i F$, mà còn trong các báo khác như Sự thật (Правда), Sụ thật Thanh niên (KП Комсомольская Правда), Вáo Văn hoc (ЛГ - Литературная газета)...

Theo quan sát của chúng tôi, câu hỏi trong các tiêu đề báo phong phú, đa dạng về chủng loại.

\subsubsection{Về cấu tạo}

Câu hỏi trong các tiêu đề báo có thể là câu đơn hoặc câu phức, câu một thành phần hay 
hai thành phần, nhiều trường hợp tiêu đề là tổ hợp gồm 2 câu riêng biệt... Ví dụ:

- Câu một thành phần

Поворот к дню рождения? (Правда 12.10.1995)

Металл из нефти? (Спутник № 1, 1987)

На «Тибет» и суда нет? (КП 10.12.1997)

- Câu đơn

Велик ли уровень ксенофобии в России (АиФ 30.08.2017)

Кто поздравил Путина с победой (АиФ 21.03.2018)

Кого в России считают кумирами ХX века? (АиФ 31.01.2018)

- Câu phức

Что будет, если вовремя не поверить счетчики воды? (АиФ 31.01.2018)

Скем боевать правительству, если БАБ в сылке, а ЧВС - в осадке? (КП 07.05.1998)

Почему звезды прощаются, но не уходят с сиены? (АиФ 31.01.2018)

- Tổ hợp các câu đơn hoặc phức với cấu trúc ngữ pháp khác nhau tạo ra những tiêu đề “độc, lạ":

Подъем - за деньги. Появятся ли в России платные лифтын? (АиФ 14.03.2018)

Русский человек - не Обломов, не Рахметов. А кто? (КП 07.05.1998)

Инициатива, созидание... Есть ли в нашей жизни что-н. более ценное, чем эти человеческие проявления? (МК 24.06.1992)

Крым. Что впереди? (АиФ 05.02.1994)

Впрочем, кто сказал, что Западу нужны наши реформыз? (МК, 30.01.1996)

\subsubsection{Về dạng thức}

Các câu hỏi trong các tiêu đề báo Nga thường có dạng sau:
- Câu hỏi có tù̀ hỏi (Câu nghi vấn có từ nghi vấn). Các từ nghi vấn $\kappa m o, 4 m o$, чeŭ, почему, когда, зачем, сколько... thường đứng ở đầu câu tiêu đề, cuối câu thường là dấu chấm hỏi. Ví dụ:

На что вам хватает зарплаты? (РГ 14.09.2004)

Сколько денег нужно для армии? (АиФ 17.01.2018)

Что в новой программе вооружений? (АиФ 28.02.2018)

Когда пенсии повысят до 25 тысяч рублей? (АиФ 21.02.2018)

Откуда в Россию едут мигрантыз (АиФ 14.02.2018)

Кто на кого жалуется на ЦИК? (АиФ 31.01.2018)

Trong một số trường hợp sau từ nghi vấn động từ dùng ở dạng nguyên thể.

Как жсить, если область - банкрот? (АиФ 31.01.2018)

Зачем считать сугроб с машины? (АиФ 14.02.2018)

- Câu hỏi không có tù̀ hỏi (Câu nghi vấn không có từ nghi vấn). Về cấu trúc, loại câu này trùng với câu trần thuật/tường thuật, cuối câu bắt buộc có dấu chấm hỏi. Ví dụ:

Русский бум на германских аукционах? (НГ 11.03.2005)

Новая Кавказская война начнется в старом московском метро? (КП 24.06.1998)

Дядя Cmеnа - коррупичионер? (КП 30.07.1998)

- Câu hỏi có tiểu tù̀ лu, pazвe hoăc tù правда:

Разве достаток - это недостаток? (Спутник № 9, 1987)

Додут ли деньги до Беслана? (КП 09.09.2004) 
Надежны ли наши банки? (АиФ 31.08.1995)

Правда, что за поддельный телосмотр будут сажать в тюрьму? (АиФ 31.01.2018)

Правда, чтов Москвеможнопосмотреть кино бесплатно? (АиФ 31.01.2018)

- Câu hỏi lựa chọn với liên từ или

Малина или аспирин? (АиФ 03.12.2009)

Царь или Родина? (АиФ 17.10.2010)

Лидер или неудачник? (АиФ № 44, 2010)

Hiệu ứng của các câu hỏi lụa chọn tăng lên nhiều lần khi nhà báo kết hợp hai hay nhiều thủ pháp ngôn ngữ. Độc giả khó có thể thờ ơ với những bài báo có cặp từ trái nghĩa trong tiêu đề sau:

Предатель или патриот? (НГ, 10/3/2005) - Kẻ phản bội hay người yêu nước

130 млрд ущеерба от коррупции -много или мало? (АиФ 16.08.2017) - 130 tỉ thất thoát vì tham nhũng: nhiều hay ít?

Школа в России и в США: обе хуже или обе лучше? (РГ, 14/9/2004) - Trường phổ thông ở Nga và Mỹ: ở cả hai nơi cùng tồi đi hay tốt lên?

\subsection{Giải mã câu hỏi trong tiêu đề báo Nga}

Theo Pađucheva "cần phân biệt loại câu hỏi thực sự và câu hỏi không đòi hỏi câu trả lời” (Падучева, 2009: 252). Điều này nghĩa là có những câu hỏi nhất thiết cần câu trả lời và có câu hỏi không cần câu trả lời trực tiếp.

\subsubsection{Câu hỏi đòi hỏi phải có câu trả lời}

Dạng câu hỏi này thường được sử dụng trong những mục hỏi-đáp các kiến thức về luật pháp, về khoa học thường thức, các bài tư vấn ...Ví dụ:

Как "ожила" планета? (Спутник, 2/1987) - Hành tinh đã "sống lại” như thế nào?

Почему мы живём в этой Вселенной? (Спутник, 3/1987) - Tại sao chúng ta lại sống trên hành tinh này?
Кто может получить вклад умершего человека? (АиФ 14.02.2018) - Ai có thể nhận tiền gửi ngân hàng của người chết?

Вреден ли для печени рыбий жир? (АиФ 14.02.2018) - Mỡ (dầu) cá có hại cho gan hay không?

Các tiêu đề có câu hỏi dạng này không hiếm trên báo chí, độc giả có thể dễ dàng tìm được điều quan tâm trong các bài báo đó. Ví dụ, trên tuần báo AiF ngày 31/01/2018 có tới gần hai chục bài báo mà nội dung là câu trả lời cho câu hỏi trong tiêu đề. Ví dụ:

Сколько соли можно съесть в день? Ăn bao nhiêu muối mỗi ngày là đủ?

В чем причина появление веснушек зимой? - Tại sao tàn nhang xuất hiện vào mùa đông?

Что можно приготовить из мха? Rêu có thể làm những món gì? (Các món có thể chế biến từ rêu?).

Как правильно принимать лекарства? Uống thuốc thế nào cho đúng? (Dùng thuốc đúng cách thế nào?)

А упало, В пропало. В каких продуктах искать витамины в зимнее время?

Сколько весит уникальный изумруд, найденный на Урале?

\section{С чем связано частое мочеиспукание?}

Câu hỏi trong các tiêu đề trên không phải là biện pháp nghệ thuật tu từ mà các nhà báo sử dụng làm "bảo bối" để tạo ra hiệu quả đích thực nhằm thu hút sự chú ý của độc giả, lôi cuốn họ tham gia vào những vấn đề mà tác giả đang bức xúc, trăn trở nên đó không phải là đối tượng nghiên cứu chính trong bài viết này. Chúng tôi sẽ đi sâu xem xét, nghiên cứu loại câu hỏi không đòi hỏi câu trả lời trực tiếp để "giải mã" chúng nhằm tìm ra những thông điệp mà tác giả muốn chuyển tải tới bạn đọc.

\subsubsection{Câu hỏi không đòi hỏi câu trả lời trục tiếp}

Dạng câu hỏi này có thể là: 
- Câu hỏi cầu khiến (вопросы-просьбы)

- Câu hỏi dạng đề nghị (вопросыпредложения)

- Câu hỏi lại (вопросы-переспросы)

- Câu hỏi tu từ (риторические вопросы) ...

Khảo sát hơn 600 tiêu đề báo dạng câu hỏi chúng tôi hầu như không thấy ba dạng câu hỏi đầu, trong các tiêu đề thường xuất hiện dạng số 4 - câu hỏi tu từ. Theo Đinh Trọng Lạc "câu hỏi tu từ về hình thức là câu hỏi mà về thực chất là câu khẳng định hoặc phủ định có cảm xúc". Dạng câu hỏi này "không đòi hỏi câu trả lời mà chỉ nhằm tăng cường tính diễn cảm của phát ngôn" (Đinh Trọng Lạc, 2005: 194).

Trong các tiêu đề báo chí Nga chức năng của những câu hỏi tu từ chủ yếu là:

- Để lôi cuốn, thu hút sự chú ý của độc giả;

- Phỏng đoán phản ứng của độc giả, ngầm định hướng cho độc giả về thái độ của họ với thông tin đó;

- Hàm chứa sự hoài nghi của tác giả về tính trung thực của sự việc, tính xác đáng của thông tin;

- Kêu gọi hành động, đề xuất biện pháp giải quyết, đề nghị.

\subsubsection{Câu hỏi thu hút sụ chú ý của độc giả}

Theo E.C.Traianxkaia, "Câu hỏi trong các văn bản viết thực sự chỉ là nhân tố gây chú ý. Câu hỏi là ngữ liệu trực quan vì thế tạo điều kiện thuận lợi cho việc thu nhận và giải nghĩa thông tin của bạn đọc. Có thể ví vai trò của câu hỏi trong văn bản viết như ngữ điệu và cử chỉ trong hội thoại” (Троянская, 1982: 158).

Trong thực tế, khi đặt tiêu đề cho bài báo, bất cứ người cầm bút nào cũng mong muốn đạt được mục đích thu hút sự chú ý của độc giả và các tiêu đề dạng câu hỏi không phải là ngoại lệ. Để đạt được mục đích này, các nhà báo đã sử dụng rất nhiều thủ pháp ngôn ngữ. a. Dùng câu hỏi lựa chọn với cặp từ trái nghĩa dùng với nghĩa bóng. Từ trái nghĩa ngũu cảnh là những cặp từ chỉ trong những ngữ cảnh cụ thể mới xác định đuợc sự đối lập của ngữ nghĩa, hiện tượng, sự vật hoặc bản chất của sự vật... làm cho tiêu đề ấn tượng, độc đáo. Ví dụ:

Недоценка или предупреждение? (Спутник, №1, 1987) - Không đánh giá đúng hay là sự thành kiến?

Босня: соглашение или перекур (Правда 29/11/1995) - Bosnhia: hiệp định ngừng chiến hay tạm nghỉ để hút thuốc?

Пуля, конечно, дура. Но умно ли ее встретить голой грудью? (КП 27.09.1995)

b. Sử dụng điệp tù, điệp ngũu trong câu hỏi là biện pháp tu từ yêu thích của nhà báo "để tạo nên ấn tượng đặc biệt và có tác dụng âm nhạc rất cao" (Đinh Trọng Lạc, 2005: 93).

Умный генерал - уволенный генерал? (КП 24/01/1995) - Tướng thông minh hay là tướng bị bãi miễn? Phải chăng họ bị bãi miễn chỉ vì nguyên nhân khó có thể chấp nhận nổi: họ quá thông minh?

Хороший русский -мертвый русский? (КП 24.10.1995)

Будет Дэн - будет и пищая? (КП 12.04.1995)

Выборы в Мытищзах - выбор 8 России? (КП 01.12.1995)

Đặc biệt, khi sử dụng biện pháp "thế đồng nghĩa" - từ đồng nghĩa (Đinh Trọng Lạc, 2005: 161), nhà báo không những diễn đạt được nội dung bài báo theo trình tự tuyến tính của phát ngôn, mà còn tạo cảm giác tò mò, gây bất ngờ. Ví dụ:

Дума отдала голоса за Кириенко. А он отдаст жизнь за изаря?

Елена Мухина знает, как выжить. $A$ кто поможет ей жить? 
В Сараево дождались трамваев. Дождутся ли переговоров?

Ельциин спас франиузов. Спасёm ли Ширак россиян?

Хоннекеру возвращена свобода. Вернётся ли здоровье?

c. Kết hợp cùng lúc các thủ pháp ngôn ngũ̃ (dấu chấm câu, đồng nghĩa, trái nghĩa...) luôn tạo ra những điểm nhấn, làm tiêu đề có tính biểu cảm cao, trông "bắt mắt".

Хотите построить дворец? Заложите свою хижину! (КП 06.08.1998) - Tiêu đề được tạo nên bởi 2 câu (câu hỏi và câu mệnh lệnh), cặp từ gần nghĩa (nocmpoumbзаложить) và cặp từ trái nghĩa (двореu хижина).

Что нама жизнь? Фильм! Фильм? Фильм ... (КП 15.07.1995)

Русский человек - не Обломов, не Рахметов. А кто? (КП 07.05.1998)

Инициатива, созидание... Есть ли в нашей жизни что-н. более ценное, чем эти человеческие проявления? (МК 24.06.1992)

Он умрет, и это интересно?... (НГ 12.04.1995)

d. Biện pháp chơi chũ trong các tiêu đề dạng câu hỏi thường dễ gây chú ý và để lại ấn tượng cho người đọc bởi sự đặc biệt và mới lạ:

Как закалялась связь (РГ 14.09.2004) Mượn và thay từ "thép" (cmaль) thành "mố $i$ quan hệ" (связь) trong tên tiểu thuyết nổi tiếng của Nhicalai Oxtrơrốpki «Как закалялась cmaль» (Thép đã tôi thế đấy).

«Фиксинг» - это «фиг всем»? (КП 04.08.1998) - Dùng từ ngoại lai fixing với nghĩa "định vị, gia cố, cố định, siết chặt..."

На чью сторону ШІЕРЕМЕТнется ОРГ? (КП 05.02.1998) (ШЕРЕМЕТнется = Шеремет + метнётся) - Bài báo về Pavel Seremet - phóng viên nổi tiếng - bị buộc tội vượt biên giới Belarus trái phép (Ông bị giết hại ngày 20.07.2016 tại Kiev, Ucraina).

По счету или по счетчику? (АиФ № 50, 2009)

Стоит ли продать себя, когда продать уже нечего? (КП 14.04.1994)

Мы наш, мы старый «мир» разрушили. И зачем? (КП 18.08.1998)

2.3.2.2. Câu hỏi phỏng đoán phản úng của độc giả, đồng tình với độc giả

Trong những trường hợp này, câu hỏi được đưa ra thường là những câu hỏi mà bản thân tác giả đã biết trước câu trả lời và đây chỉ là cách tác giả muốn chia sẻ cùng độc giả hay chính xác hơn là tác giả muốn đoán ý độc giả. Khi quyết định đặt tiêu đề cho bài báo, nhà báo thường phải cố gắng tưởng tượng ra những tình huống có thể xảy ra, tính đến nỗi hoài nghi, sự bức xúc của độc giả trong quá trình thu nhận thông tin. Thông qua câu hỏi, tác giả muốn truyền đạt thông điệp: nhà báo đã và đang đứng trên cùng chiến tuyến với họ, là đồng minh đáng tin cậy của họ. Vì vậy tác giả đã đặt mình vào chỗ của người thu nhận thông tin và công khai những ưu tư, suy nghĩ của độc giả thành câu hỏi trong quá trình thu nhận và xử lý thông tin.

Кризис финансовой совести: нас снова продали? (МК 19.11.1994)

Образуются или нет межсрракиионные блоки в думе? (МК 14.01.1996)

Выведет ли Россия войска из Сирии? (АиФ 01.11.2017)

Кто ответит за задержки зарплат? (АиФ 01.11.2017)

Будут ли санкиии за Крылский мост? (АиФ 28.02.2018)

Loại tiêu đề dạng câu hỏi này có đặc điểm là do tác giả tự đặt ra nhân danh độc giả. Ở đây, tác giả cùng một lúc muốn câu hỏi thực hiện ba chức năng: 
- Nêu thực chất vấn đề một cách rõ ràng, rành mạch

- Tạo cơ hội để độc giả thể hiện thái độ, quan điểm của mình về vấn đề nêu ra

- Mời mọc độc giả cùng tham gia giải quyết vấn đề trên.

Trên báo MK ngày 29.11.1994 có bài báo với tiêu đề "Куда идти России? Лидеры тоже не знают - Nước Nga sẽ đi về đâu? Ngay cả nguyên thủ quốc gia cũng không biết". Đó không chỉ là sự trăn trở, lo lắng của tác giả đối với tình trạng của đất nước, mà còn là sự lo ngại bất an của người dân.

Để cứu những ngân hàng bị ảnh hưởng bởi lệnh cấm vận, chính phủ sẵn sàng tiêu tiền tỉ, nhưng không nâng lương hưu, trợ cấp cho người dân... nên bài báo với tiêu đề "Почемy государство для банков деньги печатает, а для простых людей - нет? (- Tạm dịch: Tại sao chính phủ in tiền cho các ngân hàng, còn dân thường thì không?") có thể tìm được sự đồng cảm, sự cộng hưởng của độc giả.

Chỉ cần đọc tiêu đề Игра на нервах. Почему работодатели издеваются, а работники терпят? (АиФ 10.01.2018) - (Tạm dịch: Trò chơi cân não. Tại sao chủ doanh nghiệp nhạo báng, chế giễu, còn người làm công phải chịu đựng?) bạn đọc đã hình dung được nghịch cảnh đang diễn ra không chỉ ở nước Nga. Nội dung bài báo đã chỉ ra rằng Nga có 4 triệu dân đang tìm việc làm. Những người khác lo sợ mất việc và không có nguồn thu nhập khác để sinh sống, vì thế đôi khi họ phải thực hiện yêu cầu vô lý của chủ.

Trên các mặt báo, có thể dễ dàng bắt gặp những tít dạng:

Маленькие зарплаты и жеские штрафы. На что жалуются граждане РФ? (АиФ 14.02.2018)

Доходное место. Почему высшие чиновники обходятся нам так дорого? (АиФ 10.01.2018)
Почему чиновники обманывают самых беззамиттных? (АиФ 14.02.2018)

Сколько Бревновых надо убрать с дороги, ведущей в Кремль-2000? (КП 04.02.1998)

Bằng những câu hỏi mang tính thời sự cao, tác giả bài báo chứng tỏ họ luôn có những đồng minh thực sự là bạn đọc: họ có thể tìm được tiếng nói chung.

\subsubsection{Câu hỏi ẩn chứa sụ hoài nghi của tác giả vào tính chân thực của sự việc, độ chính xác của thông tin}

Thông qua câu hỏi, chính xác hơn là nhờ sự trợ giúp của câu hỏi, tác giả có thể thể hiện sự hoài nghi, không tin tưởng của mình về một sự việc, hiện tượng nào đó mà vẫn tránh được cảm giác áp đặt mang tính chủ quan, vẫn được "an toàn".

Ví dụ điển hình trong trường hợp này là bài trên Báo Văn học ngày 21.06.1995 với tiêu đề "Прощзаŭ оружиe?" viết về chấm dứt xung đột ở Tretrnhia và sự đầu hàng của đội quân của Đuđaev. Tác giả hoài nghi, không tin tưởng vào khả năng chiến sự ở đó có thể chấm dứt, bởi vậy người ta khó có thể giải trừ quân bị. Sự hoài nghi không tin tưởng đó được tác giả thể hiện bằng cách "mượn" tên tác phẩm nổi tiếng của Ernest Hemingway ( $A$ Farewell To Arms - Giã tì vĩ khi) cùng với cách sử dụng dấu chấm câu rất ấn tượng, rất đặc biệt: dấu chấm hỏi sau câu mệnh lệnh thức. Đây quả thực là thách đố với các dịch giả khi muốn dịch tiêu đề này sang ngôn ngữ khác. Rõ ràng kết hợp tuyệt vời này đã ngầm thông báo một kết quả trái ngược.

Надежны ли наши банки? (АиФ 31.08.1995) Minh chứng để chứng minh "độ tin cậy" của một số ngân hàng là lời cảnh báo cho người dân nên cẩn trọng khi lựa chọn.

Các tiêu đề dạng câu hỏi sau đây trên thể hiện rõ ràng thái độ hoài nghi của tác giả. Đây 
không còn là câu hỏi nữa mà chính là sự không đồng tình của tác giả với sự kiện, thông tin nêu ra trong bài báo. "Кто сказал, что будет лучше?”. Trong bài, câu hỏi được đặt ra quá đơn giản tới mức gần như lời thách đố và tác giả ngầm thông báo câu trả lời: Kết cục của sự việc là tình hình kinh tế Nga khó có thể khá lên được, đồng thời ngầm phê phán chính sách tài chính của đất nước. Còn về đề xuất "Бесnлатныŭ обед. За чей счёт?" trong ЛГ 10.01.1990 rõ ràng là không khả thi. Câu hỏi gián tiếp "liệu có hay không âm mưu mưu sát": " $А$ было ли покушение? (АиФ 31.08.1995) giúp tác giả bày tỏ quan điểm của mình: nghi ngờ, không tin vào tính chân thực của thông tin cho rằng Tổng thống Azerbaidzan bị mua chuộc, đồng thời khẳng định thông tin này là giả dối.

Những tiêu đề dạng này không hiếm trên báo Nga. Ví dụ:

Поворот к дню рождения (Правда 12.10.1995)

«Демократыл спасли Россию от голода? (Правда 11.11.1995)

Впрочем, кто сказал, что Западу нужны наши реформыз (МК, 30.01.1996)

Правда, что в Москве можно посмотреть кино бесплатно? (АиФ 31.01.2018)

2.3.2.4. Câu hỏi nhằm mục đích kêu gọi cùng hành động, đề xuất biện pháp giải quyết, đề $n g h i$

Là nhân tố tác động (trực tiếp hoặc gián tiếp) đến độc giả, câu hỏi trong tiêu đề giúp độc giả định hướng để có thể tìm được lời giải cho 3 vấn đề:

- Một khi đây là câu hỏi của chính tác giả vậy thì ai sẽ là người trả lời câu hỏi: tác giả hay bạn đọc?

- Những câu hỏi này giúp gì cho việc thể hiện khuynh hướng đánh giá của bài báo?
- Những câu hỏi này giúp bạn đọc có hành động/suy nghĩ gì để cải thiện/giải quyết vấn đề?

Почему коррупиию в Дагестане не замечали несколько лет? (АиФ 21.02.2018) - Tác giả không tin là trong nhiều năm nạn tham nhũng ở Đaghestan không ai nhận ra: người ta không muốn, không thích nói hoặc sợ nói ra sự thật bởi bộ máy thanh tra, kiểm soát cồng kềnh bao gồm nhiều thành phần và kiểm tra thường xuyên! Thông điệp của người viết: người dân muốn và có quyền được biết là số tiền họ đóng thuế đi đâu-về đâu và cần thiết lập hệ thống kiểm tra toàn dân.

Из-за чего растут иеены бензина? (АиФ 21.03.2018) - Với tỉ giá 70 rúp/đôla thì 1 lít xăng 95 ở Nga sẽ có giá là 50 cent, còn hiện tại đã lên tới hơn 70 cent nếu qui đổi ra tiền đô. Như vậy người tiêu dùng bị "móc hầu bao" thêm 20 cent!!! Và tác giả rút ra kết luận rất đặc biệt: «Что-то здесь не так!»

Những đề xuất về các giải pháp cần có sự cộng hưởng của bạn đọc để có thể trở thành khả thi xuất hiện nhiều trong AiF ngày 30.08.2017 và 21.03.2018:

Как государство может уменьшить разрыв между бедными и богатыми?

Как будет развиваться отечественная легкая промышиенность?

Как продать рекордный урожай?

Почему в магазинах импортный помидор?

Почему нет скидок на неудобные места в самолете?

Можно ли вернуть стоимость нерасходованных средств по ОМС?

Как вернуть гражданам РФ ощущение зашчищенности?

Đọc những tiêu đề có hai vế sau, độc giả dễ dàng nhận thấy: vế đầu chính là chủ đề mà bài báo đề cập, vế sau là khúc mắc/ băn 
khoăn/ bức xúc/ mối quan tâm chưa có lời giải và cần được giải đáp. Những giải pháp đề cập trong bài báo rất cần sự cộng hưởng, sự ủng hộ của người dân.

A библиотека - что может она? (ЛГ 09.12.1987)

Сладкая ягода - где она? (МК 20.08.1988)

Закон о печати: Каким ему быть? (Правда 08.01.1990)

Реформы-ради чего? (АиФ 05.02.1994)

Trong một số trường hợp câu hỏi trong tiêu đề bài báo còn có thể thực hiện chức năng: diễn đạt vấn đề, tạo tình huống, thông báo về dụ định của tác giả. Nói một cách văn chương hơn câu hỏi tạo điều kiện cho sự khai thông, mở đầu "câu chuyện". Ví dụ: Tác giả mở đầu bài báo bằng câu hỏi «Почему официальные лица на Западе и на Украине клевешут нашу страну, а мы молчим?» (Тạm dịch: Tại sao quan chức các nước phương Tây và Ucraina vu khống đất nước chúng ta mà chúng ta lại im lặng?”). Đây mới đích thực là câu hỏi cần có lời giải và lời giải đó được tác giả nêu trong tiêu đề: "Как России защитить свою честь?” - (АиФ 23.08.2017). - Nưóc Nga cần bảo vệ danh dụ nhu thế nào?/Nga cần làm gì để bảo vệ danh dụ? /LB Nga: Nhũng điều cần làm để bảo vệ danh dụ.

Россию уважают или боятся? (АиФ 31.01.2018) - Câu hỏi có chủ thể bất định "Người ta tôn trọng hay sợ Nga" gây chú ý bởi:

- "Người ta" trong trường hợp này chỉ các nước phương Tây, Mỹ và Ucraina (cả tác giả và bạn đọc đều hiểu rõ điều này).

- Theo ngữ pháp tiếng Nga sau động từ «уважать» danh từ sử dụng ở cách 4 , còn «бояться» - cách 2, vì vậy lẽ ra câu chuẩn phải là «Россию уважсат или России боятся?». Nhưng sự cố ý "lệch chuẩn" làm cho tiêu đề ngắn gọn hơn và có thể bạn đọc sẽ hiểu theo chiều hướng rằng, tác giả mong muốn Nga được "tôn trọng” hơn là "sợ”.

Почему материнство вылило из моды? (АиФ 28.02.2018) - Tình trạng dân số sụt giảm là đe dọa lớn đối với nước Nga. Đây là vấn đề nghiêm trọng, mang tính nguy hại cho nền an ninh quốc gia, vì vậy, tìm ra nguyên nhân và giải pháp luôn là tâm điểm của sự chú ý ở LB Nga.

Почему судьи оказались вне закона? (АиФ 14.02.2018)

\section{Kết luận}

Sự xuất hiện các câu hỏi trong các tiêu đề báo chí Nga tạo cho độc giả cảm giác được tôn trọng, được tin cậy. Đây thường cũng là những vấn đề nóng hổi của xã hội đang được rất nhiều người quan tâm, những bức xúc của người dân cần/chưa tìm được lời giải. Do đó, những tiêu đề dạng câu hỏi thường gợi trí tò mò, có sức hấp dẫn, đủ sức thu hút độc giả đón đọc. Những thông điệp mà nhà báo muốn truyền tải đến bạn đọc đáng để mỗi người suy ngẫm và hành động.

\section{Tài liệu tham khảo}

\section{Tiếng Việt}

Đinh Trọng Lạc (2005). 99 phuoong tiện và biện pháp tu tù̀ tiếng Việt. Hà Nội: Nxb Giáo dục.

\section{Tiếng Nga}

Милевская Т.Е. (1985). Средства выражения речевого контакта в русском языке (Вопросноответный комплекс в научно-популярных произведениях). Диссертация на соискание ученой степени к.ф.н., Ленинград.

Падучева Е.В. (2009). Высказывание и его соотнесенность с действительностью. Изд. ЛКИ, Москва.

Правила русской орфографии (1956). Москва.

Троянская Е.С. (1982). Лингвистическое исследование научной литературы. Москва. 


\title{
DECODING QUESTION HEADLINES IN RUSSIAN NEWSPAPERS
}

\begin{abstract}
Vu Thi Chin
Faculty of Russian Language and Culture, VNU University of Languages and International Studies, Pham Van Dong, Cau Giay, Hanoi, Vietnam

Abstract: The relations between journalists and readers can clearly be seen in question headlines. Questions in newspapers do not aim at receiving feedback; rather, they contain important information. They are just a means used by journalists to help them get closer to readers, engage them, and act as a questioner and interlocutor. This is also a method used by journalists to prepare some information for readers in order to encourage them to read their articles, and seek for readers' agreement. This paper aims to analyze different types of questions in newspaper headlines and find out messages, implications... which journalists want to express.
\end{abstract}

Keywords: journalistic style, headline, question, message 